\title{
Finite element analysis and formability of non-isothermal deep drawing of AZ31B sheets
}

\author{
Tyng-Bin Huang ${ }^{\text {a, } *}$, Yung-An Tsai ${ }^{\text {a }}$, Fuh-Kuo Chen ${ }^{\mathrm{b}}$ \\ ${ }^{a}$ Department of Mechanical Engineering, St. John's University, 499, Sec. 4, Tam King Road Tamsui, Taipei, Taiwan, ROC \\ ${ }^{\mathrm{b}}$ Department of Mechanical Engineering, National Taiwan University, Section 4, 1 Roosevelt Road, Taipei, Taiwan, ROC
}

\begin{abstract}
Magnesium alloys exhibit poor formability at room temperature, but the formability can be improved at elevated temperature. In this study the formability and non-isothermal deep drawing at elevated temperature of magnesium alloy AZ31B sheets is studied by experiment and finite element analysis. The forming temperature, lubricant and sheet thickness are considered in this study. The experimental results indicate that the highest limit drawing ratio (LDR) is at a forming temperature of $260^{\circ} \mathrm{C}$ for $0.58 \mathrm{~mm}$ thick AZ31B sheet, and the highest LDR is 2.63 . The highest LDR is at a forming temperature of $200^{\circ} \mathrm{C}$ for $0.50 \mathrm{~mm}$ thick $\mathrm{AZ31B}$ sheet, and the highest LDR is 2.5 . The experimental data shows a good agreement with the simulation results.
\end{abstract}

(C) 2006 Elsevier B.V. All rights reserved.

Keywords: Deep drawing; Magnesium alloy AZ31; Finite element; Formability

\section{Introduction}

Due to the low density and high specific rigidity, magnesium alloys have the potential to reduce the weight of structural parts $[1,2]$. The formability of magnesium is low at room temperature because of the hexagonal closed packed (HCP) crystal structure. Therefore, die casting is mostly utilized for fabrications with magnesium alloys in industries. When compared to die casting, sheet metal forming shows better mechanical properties. However, warm deep drawing can improve the formability of magnesium alloy sheets because the pyramidal plane of magnesium HCP crystal structure will be operated by thermal activation and which results in good formability with warm forming [3-5].

In this study the formability and non-isothermal deep drawing at elevated temperature of magnesium alloy AZ31B sheets are studied by experiments and finite element analysis. The forming temperature, lubricant and sheet thickness are considered in this study. The commercial FEM code MSC Superform was used to simulate the deep drawing processes. Punch load and temperature distribution were obtained to validate the FEM simulation results.

\footnotetext{
* Corresponding author. Tel.: +886 228013131 x6715; fax: +8862 28013143. E-mail address: tbhuang@mail.sju.edu.tw (T.-B. Huang).
}

\section{Experiment and FEM model}

\subsection{Experiment}

Circular cup drawing tests were performed to determine the LDR and formability of magnesium alloy. Fig. 1 shows the schematic diagram of the tool. Tests were conducted with circular blanks of various diameters to determine the LDR for a given temperature. The diameters of the blank ranged from 55 to $110 \mathrm{~mm}$ with intervals of $5 \mathrm{~mm}$. Tests were performed at 100 , $150,200,230,260$ and $300^{\circ} \mathrm{C}$. The punch load and stroke were obtained by pressure transducer and potential meter. Two surface thermocouples were used to measure the temperature distribution of drawn cup, as shown in Fig. 1. Punch load, stroke, and temperature were recorded by a data acquisition card. Punch load and temperature distribution were obtained to validate the FEM simulation results. AZ31 magnesium alloy sheets of 0.58 and $0.50 \mathrm{~mm}$ thicknesses were used in the current research. Meanwhile, two kinds of lubricants (molybdenum disulfide and TYE press lubricant oil no. 5) were used to investigate the influence of lubricants to formability.

Fig. 2 shows the setup of deep drawing system for this research. Electric heaters are used for heating the die and blankholder. The electric power input to the heaters are controlled by PID controllers and thermocouples buried in the die and blankholder, and they maintained the tools at a specified temperature. Insulation plates and water-cooled plates are used to 


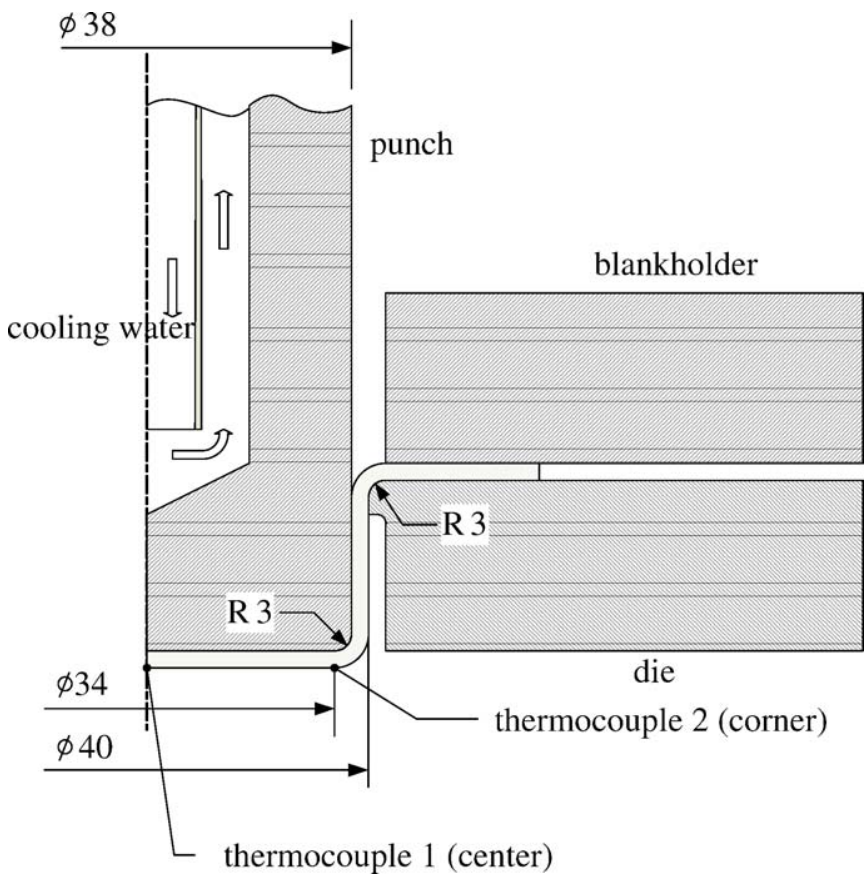

Fig. 1. Schematic diagram of the tool.

prevent the heat from transferring to the experiment equipment. The temperature of the hollow punch is kept between 10 and $15^{\circ} \mathrm{C}$ by the circulation cooling water provided by the chiller.

\subsection{Finite element model}

The commercial FEM code MSC Superform was employed to simulate the deep drawing processes in this study. Fig. 3 indicates the mesh configuration used for the FEM simulation model. Four layers of four-node quadrilateral elements were used in the simulations. The flow stress of AZ31B sheet obtained by Chen et al. [6] from tensile tests was used in the simulations. The effects of forming temperature upon blank temperature distribution and punch load were studied.

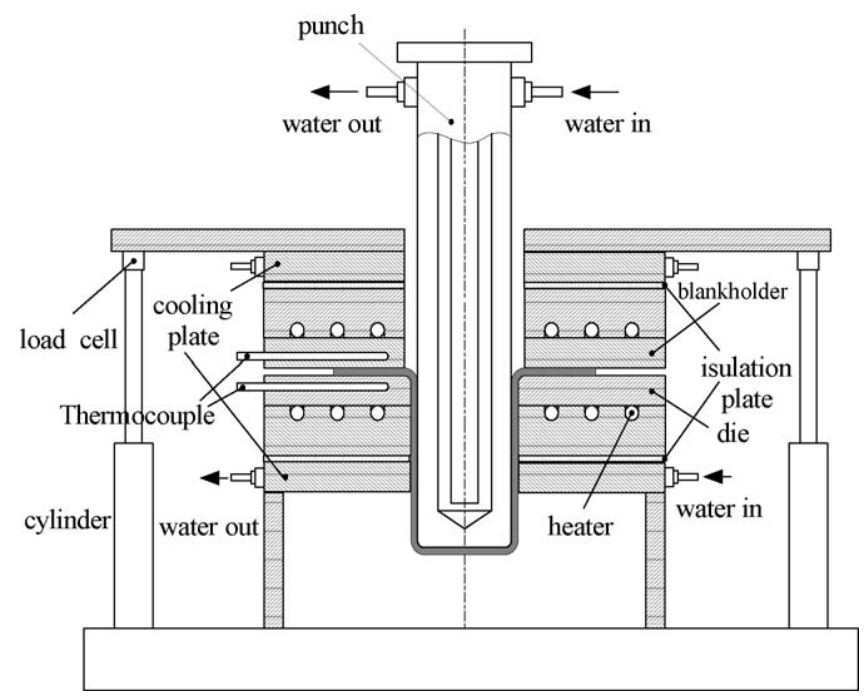

Fig. 2. Setup of the non-isothermal deep drawing system.

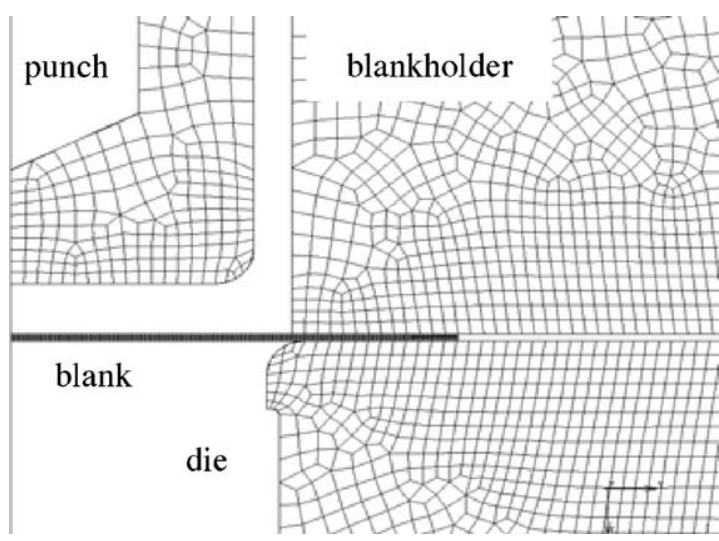

Fig. 3. Mesh configuration used for the FEM simulation model.

\section{Results and discussions}

\subsection{Temperature distribution}

Fig. 4 shows the temperature distribution of the blank at different punch travel with the die and blankholder temperature at $260^{\circ} \mathrm{C}$. According to the simulation results, the temperature of the blank near the punch corner was lowered because of the contact with water-cooled punch, and its strength was increased. Under isothermal deep drawing if the drawing ratio is too high, the blank will fracture near the punch corner because of local thinning. Under non-isothermal deep drawing, the fracture position will be at the die corner because the strength of the blank near the punch corner is increased. So, the LDR will be increased. Fig. 5 shows the locations of fracture by FEM simulations and experiments. Fig. 6 shows the comparison of the blank temperature distribution in simulations and experiments. Two surface thermocouples were set at the bottom of the drawn cup, one at the center and the other one at a distance $17 \mathrm{~mm}$ from the center as shown in Fig. 1. After the punch touches the blank, the temperature of the blank will be lowered fast and the temperature drop at the center will be faster than that of the corner. The temperature drop observed in experiment is slower than that of simulation. The reason could be due to the incomplete contact between the punch and the bottom of the cup. Although there is deviation between the simulation result and experiment result, the simulation can predict the temperature distribution

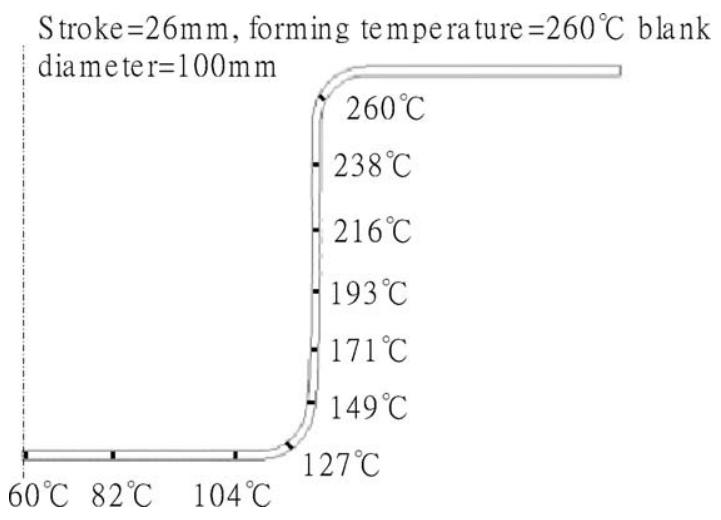

Fig. 4. Temperature distribution of the blank. 


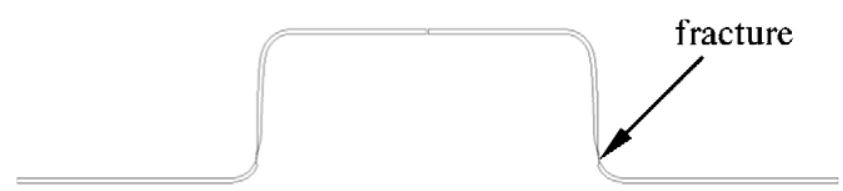

blank diameter : $105 \mathrm{~mm}$

forming temperature : $260^{\circ} \mathrm{C}$ stroke : $17 \mathrm{~mm}$

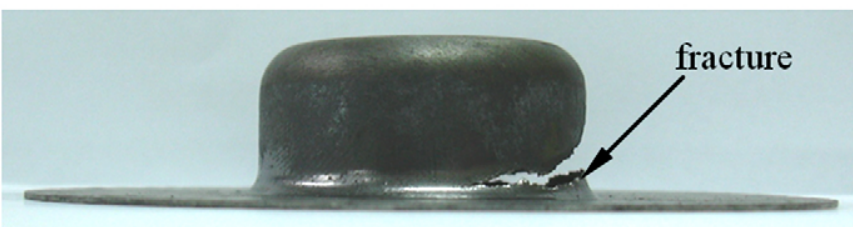

Fig. 5. Locations of fracture by FEM and experiments.

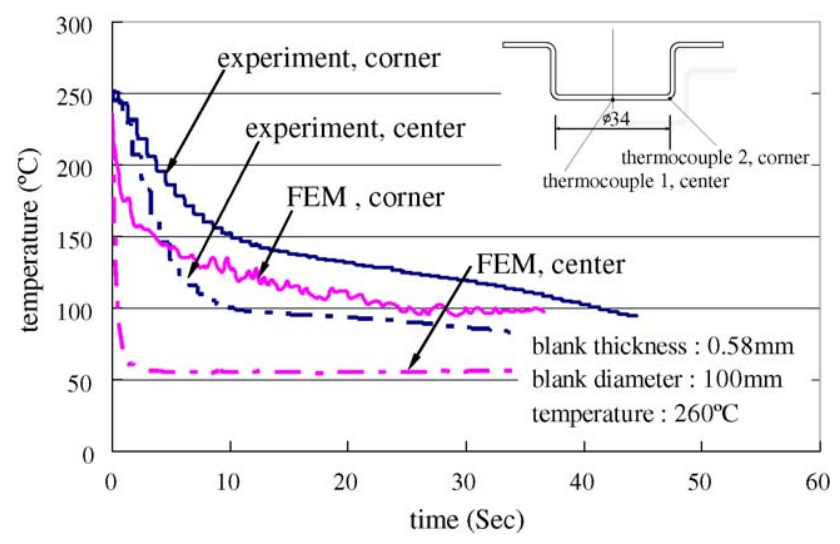

Fig. 6. Blank temperature by FEM and experiments.

and then used to estimate the temperatures of the positions that are difficult to be measured by experiment.

\subsection{Punch load-stroke}

Fig. 7 shows the punch load versus stroke obtained from simulations and experiments with different diameter blanks for the forming temperature at $300{ }^{\circ} \mathrm{C}$. The diameters of the blank

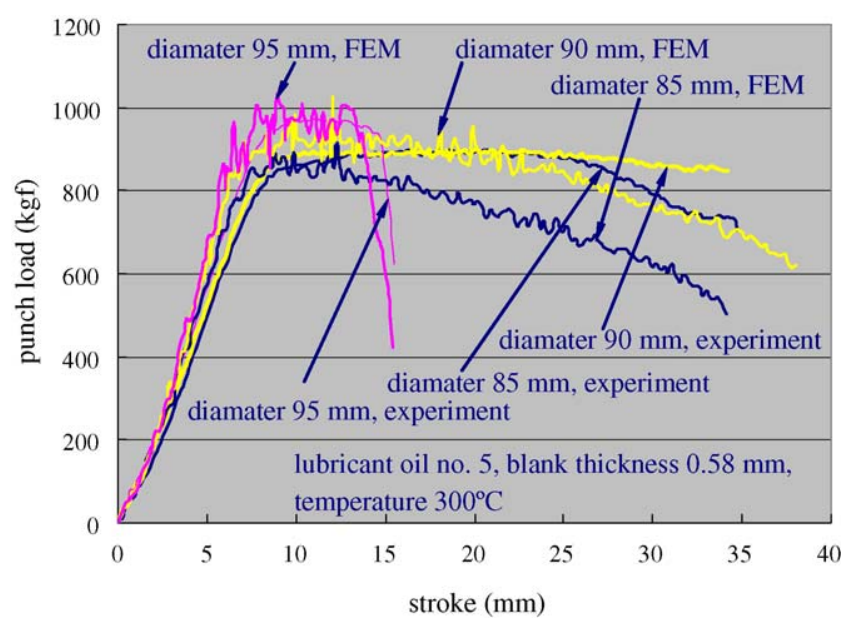

Fig. 7. Punch load-stroke from FEM and experiments.

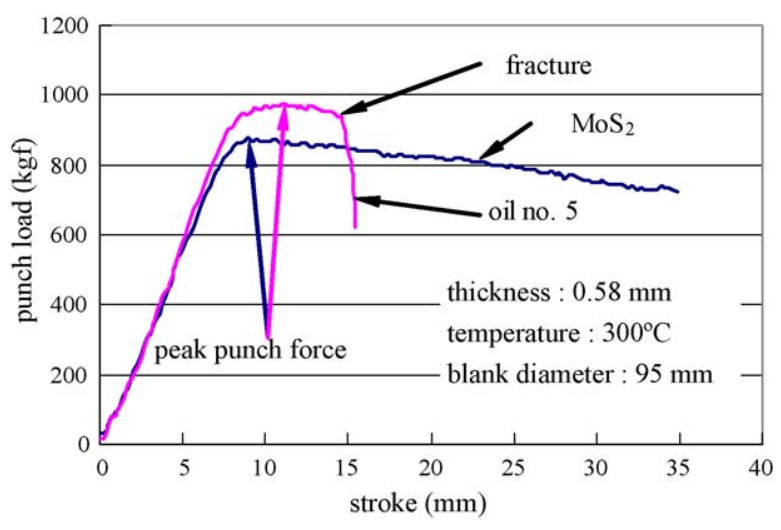

Fig. 8. Load-stroke from experiments with different lubricants.

are 85,90 and $95 \mathrm{~mm}$. The fluctuation in the load-stroke curve in the simulation is due to the oscillation of node in contact with the punch [7]. There is a peak punch force, and the punch load decrease after the stroke larger than the peak force. Due to the decreasing of flange area, the force required to pull the blank into the die will decrease. The peak punch force is increased as the diameter of blank is increased [8]. When the peak punch force is higher than the limit strength of the cup wall, the blank will fracture, and the punch force will decrease suddenly. When the peak punch force is lower than the limit strength of the cup wall, the blank will be drawn successfully, and flow into the die cavity.

Fig. 8 shows the punch load versus stroke obtained from experiments with different lubricants at the forming temperature $30{ }^{\circ} \mathrm{C}$. The peak punch force with molybdenum disulfide is lower, and the blank can flow into the die cavity successfully. The peak punch force with oil no. 5 is higher than limit strength, and the blank will fracture. That is because the friction coefficient of molybdenum disulfide is lower than that of oil no. 5 .

\subsection{Limiting drawing ratio}

The LDR was used to investigate the formability of AZ31B sheets. The effects of forming temperature, lubricants and thickness of sheets were examined. Fig. 9 shows the relations between the forming temperature and the LDR of two lubricants from

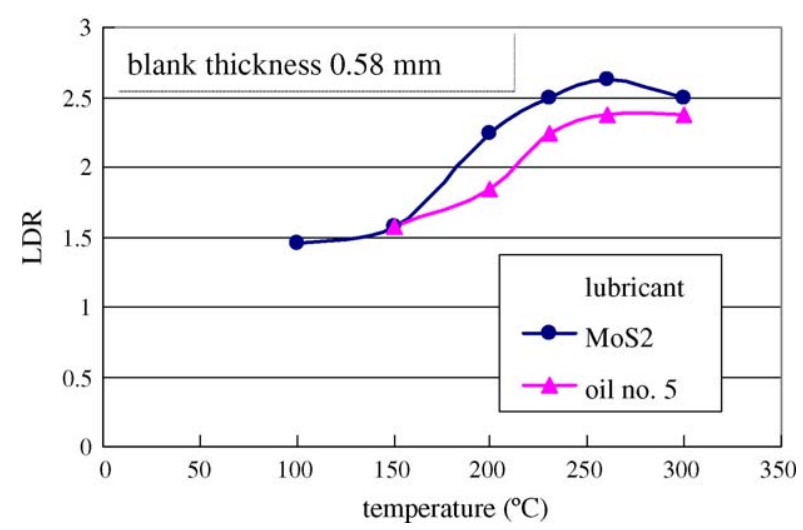

Fig. 9. LDR from experiments at various forming temperature. 


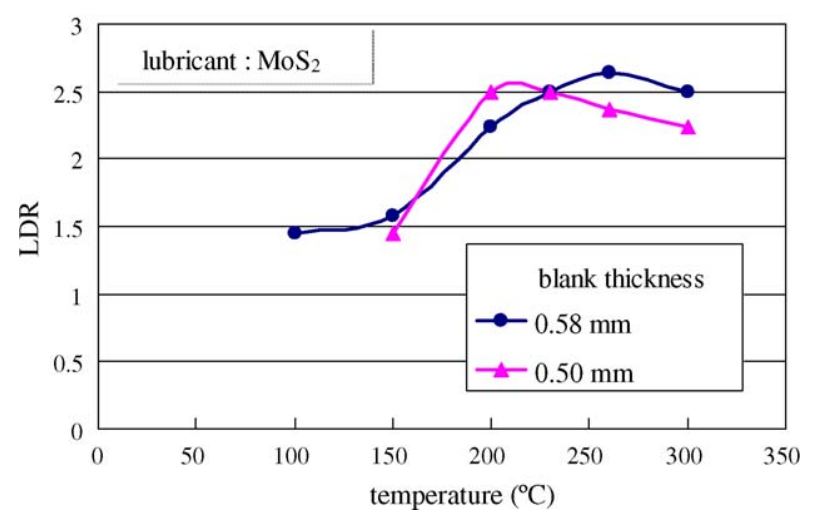

Fig. 10. LDR of various sheet thickness from experiments.

experiments. Both the molybdenum disulfide and oil no. 5 experiment data show the highest LDR at $260{ }^{\circ} \mathrm{C}$ for $0.58 \mathrm{~mm}$ thick AZ31B sheet. The decrease of LDR at temperature higher than $260{ }^{\circ} \mathrm{C}$ is due to the lower of work hardening exponent at higher temperature that induces local thinning of the sheet near the die corner. The curve of molybdenum disulfide is higher than the curve of oil no. 5. That is because the peak punch force is lower when molybdenum disulfide is used, as shown in Fig. 8. Fig. 10 shows the relations between the forming temperature and the LDR of two different thicknesses of sheets from experiments. The LDR is the highest at $200^{\circ} \mathrm{C}$ for $0.5 \mathrm{~mm}$ thick AZ31B sheet.

\section{Conclusions}

Finite element simulations and experiments were used to investigate the formability and non-isothermal deep drawing at elevated temperature of magnesium alloy AZ31B sheets. The major conclusions are as follows.

1. In the non-isothermal deep drawing of AZ31 sheet, the LDR is higher than that of conventional deep drawing. This is due to the strength of the blank near the punch corner is increased.
2. The peak punch force is increased as the diameter of blank is increased. When the peak punch force is higher than the limit strength of the cup wall, the blank will fracture, and the punch force will decrease suddenly.

3. Both the molybdenum disulfide and oil no. 5 experiment data show the highest LDR at $260^{\circ} \mathrm{C}$ for $0.58 \mathrm{~mm}$ thick AZ31B sheet, and the highest LDR is 2.63 for molybdenum disulfide and 2.37 for oil no.5. The LDR is the highest at $200^{\circ} \mathrm{C}$ for $0.5 \mathrm{~mm}$ thick AZ31B sheet, and the highest LDR is 2.5.

\section{Acknowledgement}

The author would like to thank the National Science Council of the Republic of China for financially supporting this research under Contract No. NSC 93-2212-E-129-006, which makes experimental works possible.

\section{References}

[1] B.L. Mordike, T. Ebert, Magnesium properties-application-potential, Mater. Sci. Eng. A302 (2001) 37-45.

[2] H. Furuya, N. Kogiso, S. Matunaga, K. Senda, Applications of magnesium-alloys for aerospace structure systems, Mater. Sci. Forum 350-351 (2000) 341-348.

[3] E. Doege, K. Droder, Sheet metal forming of magnesium wrought alloysformability and process technology, J. Mater. Process. Technol. 115 (2001) 14-19.

[4] J. Kaneko, M. Sugamata, M. Numa, Y. Nishikawa, H. Takada, Effect of texture on the mechanical properties and formability of magnesium wrought materials, J. Jpn. Instit. Metals 64 (2000) 141-147.

[5] H. Takuda, H. Fujimoto, N. Hatta, Modelling on flow stress of Mg-Al-Zn alloys at elevated temperatures, J. Mater. Process. Technol. 80-81 (1998) 513-516.

[6] F.-K. Chen, T.-B. Huang, C.-K. Chang, Deep drawing of square cups with magnesium alloy AZ31 sheets, Int. J. Mach. Tool Manu. 43 (2003) 1553-1559.

[7] H. Palaniswamy, G. Ngaile, T. Altan, Finite element simulation of magnesium alloy sheet forming at elevated temperatures, J. Mater. Process. Technol. 146 (2004) 52-60.

[8] M. Jain, J. Allin, M.J. Bull, Deep drawing characteristics of automotive aluminum alloys, Mater. Sci. Eng. A256 (1998) 69-82. 